\title{
The use of educational technologies in teaching the course "gender approach in the practical activities of the teacher"
}

\author{
N.A. Gluzman ${ }^{1 *}$, O.I. Vaganova ${ }^{2}$, and E.A. Chelnokova ${ }^{3}$ \\ ${ }^{1}$ V.I. Vernadsky Crimean Federal University, Simferopol, Russia \\ ${ }^{2}$ Minin Nizhny Novgorod State Pedagogical University, Nizhny Novgorod, Russia \\ ${ }^{3}$ Minin Nizhny Novgorod State Pedagogical University, Nizhny Novgorod, Russia
}

\begin{abstract}
Current trends in the development of continuing education require the use of innovative technologies to improve the quality of the learning process. The article aims of is to study the experience of the use of educational technologies in teaching a continuing education course "Gender Approach in the Practical Activities of Educators". The increasing importance of a gender approach around the world makes it necessary for teachers to study the aspects of gender interaction among students. The article presents the development of the structure and content of the ecourse "Gender approach in the practical work of the teacher". The course is implemented using innovative educational technologies, methods and tools used by leading higher education institutions. Its implementation It is carried out by teachers using information, design, case studies, gaming, and other innovative educational technologies. The professional development course is aimed at developing students' competencies related to the harmonization of students' gender-role interaction, which is considered as the principle of ensuring equal rights and opportunities regardless of gender. The course structure is represented by a wide theoretical block and a practical part. The course develops students 'competencies, including the ability to form students' tolerance for perceiving the position of another person and correctly arguing their opinion in interaction with their. Their use broadens the possibilities of training students, contributes to the formation of their competencies. Improving the quality of training of listeners proving e $t$ efficiency realized by the course, and the increase in the number of listeners - its relevance.
\end{abstract}

\section{A problem statement}

The modern educational paradigm has led to the emergence of a trend towards lifelong learning [26]. In this regard, the demand for additional education courses has significantly increased [1]. Improving the efficiency and quality of the learning process in the context of Informatization [2], mass communication and globalization require the implementation of new educational technologies in the system of additional professional education [27]. In

*Corresponding author: ipcs-profped@yandex.ru 
this process, there is an interest in the implementation of advanced technologies in the framework of advanced training courses [28]. In this article, we consider the implementation of educational technologies in the process of teaching advanced training courses and "Gender approach in the practical activity of a teacher" [23].

The modern educational system reacts to the increasing role of egalitarianism [3]. Modern teachers, carrying out their professional activities [25], increasingly rely on the basic principles of this direction of state policy [4]. Many researchers turn to the theory of gender attitudes to study the impact of gender interaction on the educational process [5]. Gender interaction - the interaction of individual subjects in the process of gender socialization. An important factor in the process of training students is the culture of interaction, which is interpreted as a system of gender relations, including universal, national, personal values that involve students in performing various gender roles.

The current process of teaching from a gender perspective requires a review of the organization of training [7]. The advanced training courses that we develop are aimed at forming students ' holistic views on gender aspects of education, as well as developing competencies related to solving current pedagogical problems from the perspective of gender approach [24].

This course is intended for teachers, as well as those interested in harmonizing the roleplaying interaction of students.

The course is implemented using innovative educational technologies, methods and tools used by leading higher education institutions [6]. The use of innovative educational technologies in domestic and foreign research is one of the most relevant topics. In our work, we are based on the opinion of G.I. Ilyin, who notes that innovative educational technologies allow you to achieve your goals, thanks to a clearly defined algorithm of actions.

The course structure is represented by a wide theoretical block and a practical part. The course includes the study of such topics as "Gender aspects of the family", "Socialization", "Basics of gender pedagogy", "Male and female roles in modern society", "Features of training of women and men. Theoretical aspect".

The professional development course is aimed at developing students' competencies related to the harmonization of students' gender-role interaction, which is considered as the principle of ensuring equal rights and opportunities regardless of gender [8]. The course develops students 'competencies, including the ability to form students' tolerance for perceiving the position of another person and correctly arguing their opinion in interaction with their opponent [22].

The purpose of the professional development course "Gender approach in the practical activity of a teacher": the development of students ' competencies related to the harmonization of gender-role interaction of students, considered as the principle of ensuring equal rights and opportunities regardless of gender [10]. The course contributes to the formation of students ' holistic views on the gender aspects of education [11], the resolution of current pedagogical problems from the perspective of gender approach [12], the effective application of gender knowledge in practice [13].

The course structure is represented by a wide theoretical block and a practical part. The course length is 108 hours, where 36 hours are allocated for lectures, 72-for independent work.

\subsection{The objective of the work}

Egalitarianism is a trend based on the idea of political, economic, social and civil equality of all members of society, men and women [17]. Pedagogical aspects of gender interaction are becoming relevant topics for research by many scientists [18]. In this interaction, an 
important role is played by individuality - the uniqueness of a person, the variety of life features. L.I. Stolyarchuk speaks about male and female individuality as an integral, integral "image of the Self", which must be taken into account when preparing students. The category "gender" reflects the features of interaction between men and women as socially organized groups [21]. According to V. Vdovych and S. Rykova, the Central object of gender research is the differences and similarities in the behavior of men and women in the process of interaction. The features of gender socialization are highlighted in the works of I.S. Kletsina and E.P. Ilyin.

The research was carried out based on the Institute of directed professional education, during which the content of the professional development course "Gender approach in the practical activity of a teacher" was developed and implemented.

The course implementation includes modern educational technologies, methods and. During the course implementation, various forms of educational work are used [15], which ensures the unity of theoretical and practical training. Problem lectures with discussion elements, seminars and practical classes are realized in game forms, various types of independent work, including in the form of project activities are implemented [16].

The content of the professional development course "Gender approach in the practical activity of a teacher" includes three modules: "Theoretical and methodological foundations of gender research in psychology and pedagogy"; "Gender characteristics of the individual"; "Gender approach in education".

The detailed content of the course is shown in table 1.

Table 1. The content of the advanced education course "Gender Approach in the Practical Activities of the Teacher" (as part of our study).

\begin{tabular}{|c|c|}
\hline \multicolumn{1}{|c|}{ Module } & \multicolumn{1}{|c|}{ Module Content } \\
\hline $\begin{array}{l}\text { Theoretical and methodological foundations } \\
\text { of gender researches in psychology and } \\
\text { pedagogy }\end{array}$ & $\begin{array}{l}\text { Gender researches in psychology and } \\
\text { pedagogy; } \\
\text { The emergence and development of gender } \\
\text { studies in Russian psychological science; } \\
\text { Gender approach in the history of } \\
\text { pedagogy. }\end{array}$ \\
\hline Gender characteristics of personality & $\begin{array}{l}\text { Gender identity in the system of gender } \\
\text { relations; } \\
\text { Gender roles; } \\
\text { Gender aspects of socialization. }\end{array}$ \\
\hline Gender approach in education & $\begin{array}{l}\text { Gender approach in pedagogy; } \\
\text { The effect of gender stereotypes in } \\
\text { education; } \\
\text { Methods of gender researches. }\end{array}$ \\
\hline
\end{tabular}

When implementing the course program "Gender approach in the practical activity of a teacher", innovative educational technologies are used both during classroom sessions (36 hours) and during independent work (72 hours).

In the course of studying the module "Theoretical and methodological foundations of gender research in psychology and pedagogy", students study gender issues in modern science and the stages of gender research, the relationship between the concepts of "sex" and "gender".

The course used the most modern electronic databases that allow students to get up-todate information and complete tasks.

Information technologies are implemented both during classroom sessions and during independent work (Pichugina et al., 2019). Students allowed to make extensive use of electronic learning tools [20]. Classroom classes are held in the form of lectures, where 
theoretical issues are discussed using multimedia equipment. Information is provided with the high degree of visualization.

The learning module "Gender characteristics" include gender identity as a social construct, but also psychological, socio-psychological, sociocultural factors influencing gender identity, behavior, filling the gender identity of men and women. Students complete tasks on the topics "Gender roles and culture", "Type of personality" within the framework of the electronic educational platform Moodle. They join together in creative groups and create projects. Interactive whiteboards and document cameras are used in the process of mastering the material in the classroom. Lectures include elements of discussions based on previously studied material. During the seminars, research papers by various scientists on gender issues and other materials of a problematic nature are discussed.

The third module - "Gender approach in education" includes the study of the production and reproduction of gender relations in educational institutions, gender stereotypes, their functions and causes for building a conflict-free educational process. At seminars, teachers actively use case tasks that allow students to solve problems from real practice. When performing practical tasks, students use the electronic educational platform Moodle, which uses glossaries, chat within each specific discipline, forums and webinars, and Wiki. Students perform work both individually and in a group.

To control the development of the course, comprehensive assessment work is carried out.

\section{Materials and the results of the research}

We conducted a study among students of the course "Gender approach in education". From 2016 to 2019, we measured the quality of their training with the help of comprehensive assessment work, which included testing and practical tasks. The students applied various educational technologies in the preparation of assessment work, used multimedia tools, elements of an electronic educational platform, and mastered new necessary tools for further pedagogical activities and improving the quality of student training.

Every year, the number of educational technologies used in the process of training students has increased. We tracked the change in the quality of training in dynamics.

Table 2 shows the results of the training. Grade excellent: 100-72 points, good: 71-55, satisfactory: 54-0.

Table 2. The results of statistical data processing to identify the quality of training for students of the course "Gender Approach in the Practical Activities of the Teacher" for the period from 2016 to 2019 (as part of our study).

\begin{tabular}{|l|l|l|l|l|}
\hline \multirow{3}{*}{ Rating } & \multicolumn{4}{|c|}{ Year } \\
\cline { 2 - 5 } & $\mathbf{2 0 1 6}$ & $\mathbf{2 0 1 7}$ & $\mathbf{2 0 1 8}$ & $\mathbf{2 0 1 9}$ \\
\cline { 2 - 5 } & \multicolumn{4}{|c|}{ Complex evaluative work } \\
\hline Excellent & $35 \%$ & $38 \%$ & $40 \%$ & $43 \%$ \\
\hline Good & $65 \%$ & $62 \%$ & $60 \%$ & $57 \%$ \\
\hline Satisfactorily & $0 \%$ & $0 \%$ & $0 \%$ & $0 \%$ \\
\hline
\end{tabular}

Based on the data processing methods of mathematical statistics, we have obtained results that indicate an improvement in the quality of training of students of the advanced training course. We have the right to believe that this increase was due to the influence of innovative educational technologies introduced in the course being implemented.

Students with satisfactory grades were not identified at any stage of the study. 
It is worth noting that the number of students with high scores for performing complex assessment work has increased. If in $2016,35 \%$ of students were identified with the highest score, by 2019 this figure has increased to $43 \%$.

Throughout the study, there was a tendency to increase the number of participants in the course. The results of statistical processing of data on identifying the number of listeners are shown in figure 1.

We see the dynamics of growth in the number of listeners throughout the study period.

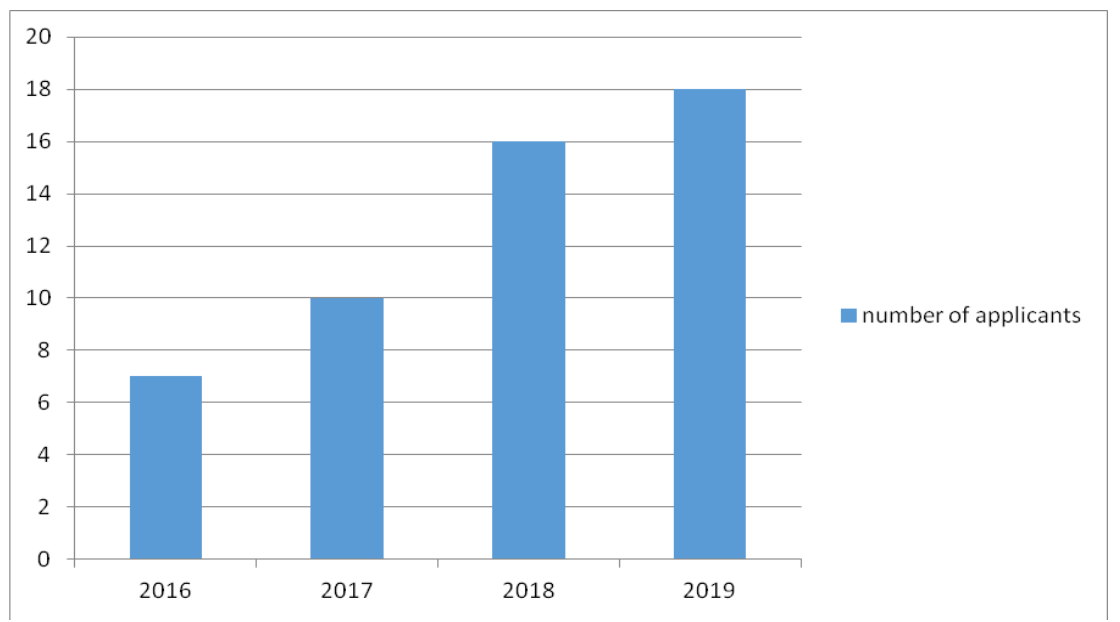

Fig. 1. Number of participants in the advanced training course "Gender approach in the practical activity of the teacher" (2016-2019) (as part of our study).

\section{Conclusions}

We conducted a study of the experience of using educational technologies in teaching the advanced training course "Gender approach in the practical activity of a teacher".

The course contributes to the construction of an integrated educational process, contains structured educational materials. The implementation of advanced training courses "Gender approach in the practical activity of a teacher" contributed to the students ' mastering of relevant competencies related to solving pedagogical problems from the perspective of a gender approach through the implementation of innovative educational technologies widely used in the training process.

The students applied various educational technologies in the preparation of assessment work, used multimedia tools, elements of an electronic educational platform, and mastered new necessary tools for further pedagogical activities and improving the quality of student training.

The data obtained in the course of the study have statistical confirmation, which indicates with a sufficient degree of objectivity the trend in the positive dynamics of the formation of students ' competencies.

The study showed an increase in the number of students who have high scores for performing complex assessment work. Every year the number of students of the course increased. Improving the quality of training students proves the effectiveness of the course, and the growth in the number of students - its demand. 


\section{References}

1. O.A. Andrienko, On the need to apply gaming training technologies, Balkan Scientific Review, 2 (4), 5-8 (2019)

2. O.A. Andrienko, Modern educational technologies: technology of self-presentation, Balkan Scientific Review, 1 (3), 5-7 (2019)

3. T.K. Andriushchenko, Personal aspects of pedagogue's innovative culture, Scientific Vector of the Balkans, 1, 13-16 (2018)

4. L.V. Aleksieienko-Lemovska, The activity approach as a basis for preschool teachers' methodological activities, Humanitarian Balkan Research, 3, 10-14 (2019)

5. N.P. Bakharev, Creativity - a prerequisite for the formation of professional competences in specialists of technical direction of training, Scientific Vector of the Balkans, 3, 17-21 (2019)

6. A.P. Cirdan, Innovative technologies of professional training of future economists in the system of continuous education, Humanitarian Balkan Research, 2 (4), 27-30 (2019)

7. O.O. Chertovskikh, Prospects for the use of digital resources in education, Baltiyskiy gumanitarnyy zhurnal (Baltic Humanitarian Journal), 4 (29), 184-187 (2019)

8. O.Y. Donetskova, Modernization of the modern education system in Russia, Baltiyskiy gumanitarnyy zhurnal (Baltic Humanitarian Journal), 2 (27), 37-39 (2019)

9. I.F. Filchenkova, Educational management of innovative activity of teachers as an object of pedagogical research, Vestnik Mininskogo universiteta (Vestnik of Minin University), 7 (4) (2019)

10. S.G. Grigoriev, V.A. Shabunina, Ju.M. Tsarapkina, N.V. Dunaeva, Electronic library system as a means of self-development of students of digital generation $\mathrm{Z}$ (on the example of studying the course "Basics of the counselor activity"), Scientific and technical libraries, 7, 78-99 (2019)

11. A.V. Gladkov, O.I. Vaganova, M.P. Prokhorova, Modern pedagogical technologies as a means of enhancing educational motivation, Baltiyskiy gumanitarnyy zhurnal (Baltic Humanitarian Journal), 1 (26), 274-276 (2019)

12. K.A. Halatsyn, A.M. Feshchuk, Diagnosing motivational-and-valuable component of the communicative culture of students in higher technical educational institutions, Balkan Scientific Review, 2 (4), 17-20 (2019).

13. G.T. Klinkov, The specificity of manifestation of pedagogical communication as a special construct, Scientific Vector of the Balkans, 1, 51-52 (2018)

14. O.M. Kobernyk, N.M. Stetsenko, V.V. Boichenko, S.M. Pryshchepa, Improving professional and pedagogical training of future teachers by moodle platforms (On the example of the course "Pedagogy"), Scientific Vector of the Balkans, 1, 5-7 (2018)

15. I.I. Oros, The role of international connections in the development of the adult education system, Humanitarian Balkan Research, 1, 57-59 (2018)

16. I.I. Osadchenko, Key concepts of situational training technology in preparing future teachers, Scientific Vector of the Balkans, 1 (3), 46-49 (2019)

17. V.M. Pliushch, Independent work of students as a factor of improving education quality. Balkan Scientific Review, 1, 69-71 (2018)

18. M.P. Prokhorova, A.A. Semchenko, Involving of trainees-future teachers of professional training in project activities in the discipline, Vestnik Mininskogo universiteta (Vestnik of Minin University), 6, (2) (2018) 
19. G.A. Pichugina, D.A. Zhilyakova, Structuring the organization of the process of creativity, Scientific Vector of the Balkans, 3, 55-58 (2019)

20. P.V. Petrichev, N.N. Masyuk, M.A. Bushueva, Method of estimation of the effectiveness of the partnership russian universities with foreign educational organizations, Azimut nauchnykh issledovaniy (Azimuth of Scientific Researches: Economics and Management), 3 (24), 229-232 (2018)

21. D.A. Pisarenko, Evaluation of extracurricular activities of university students with a competency-based approach, Scientific Vector of the Balkans, 3 (5), 37-40 (2019)

22. J. Raven, Education and Sociocybernetics, Azimut nauchnykh issledovaniy (Azimuth of Scientific Researches: Economics and Management), 3 (20), 289-297 (2017)

23. Ju.M. Tsarapkina, M.M. Petrova, A.G. Mironov, I.M. Morozova, O.B. Shustova, Robotics as a basis for Informatization of education in children's health camp, Amazonia Investiga, 8 (20) (2019)

24. Z.A. Tolkanuk, Professional self-determination of youth as a factor of training of a competent specialist, Balkan Scientific Review, 2 (4), 57-59 (2019)

25. Ju.M. Tsarapkina, N.V. Dunaeva, A.M. Kireicheva, Application of BYOD technology in education on the example of Lecture Racing mobile application, Informatika $\mathrm{i}$ obrazovanie, 9 (308), 56-64 (2019)

26. O.I. Vaganova, L.I. Ilyashenko, Zh.V. Smirnova, N.V. Bystrova, S.N. Kaznacheeva, Students' creative abilities development in higher educational institution, Amazonia Investiga, 8 (22), 701-710 (2019)

27. O.I. Vaganova, I.V. Rudenko, S.M. Markova, Zh.V. Smirnova, M.M. Kutepov, The use of educational video materials in educational process of a higher educational institution, Amazonia Investiga, 8 (22), 216-222 (2019)

28. O.I. Vaganova, Yu.A. Livshits, E.A. Aleshugina, Zh.V. Smirnova, L.I. Kutepova, Experience in developing electronic glossary in a higher education institution, Amazonia Investiga, 8 (22), 247-253 (2019) 